\title{
Powrót na planetę Auschwitz Zemdlenie Yehiela Dinura jako kluczowy moment w tworzeniu pamięci o Zagładzie
}

7 czerwca 1961 roku pisarz Yehiel Dinur wygłosił w teatrze Beit Ha’am w Jerozolimie pełen patosu monolog o odległej planecie, po czym zemdlał. Nie byłoby w tym wydarzeniu nic niezwykłego, gdyby nie fakt, że miało miejsce w ramach procesu sądowego, pisarz pełnił funkcję świadka, a teatr sądu. Proces Adolfa Eichmanna trwał od 11 kwietnia do 14 sierpnia 1961 roku i składał się ze 114 sesji. Jego źródła tkwią w samych początkach Państwa Izrael. Wkrótce po zadeklarowaniu niepodległości, w 1950 roku, Izrael uchwalił prawo dotyczące nazistów i kolaborantów, dzięki któremu można było sądzić schwytanych w przyszłości winnych ${ }^{1}$. W 1960 roku agenci Izraela odszukali i porwali byłego oficera SS Adolfa Eichmanna w celu postawienia go przed sądem. Eichmann był najwyższym rangą oficerem SS mającym bezpośrednią styczność z ludnością żydowską. Odpowiadał za jej transport do obozów koncentracyjnych, a więc osobiście zajmował się eksterminacją. Nie tworzył nazistowskich praw, ale je wykonywał. Po wojnie esesmanowi udało się uciec z Europy do Argentyny, skąd wiosną 1960 roku został uprowadzony przez izraelskich agentów służb specjalnych. 23 maja 1960 roku Dawid Ben-Gurion ogłosił aresztowanie Eichmanna, a niecały rok później rozpoczął się jego proces. Sama kwestia sądzenia go w kraju, którego obywatelstwa nie posiadał, w którym nie popełnił przestępstwa, co więcej - w kraju, który nie istniał w czasie popełniania czynów, za które się go sądzi, była wątpliwa. Proces miał charakter polityczny, a jego celem było pokazanie światu, przez co przeszedł naród żydowski, co miało legitymizować istnienie Państwa Izrael.

\footnotetext{
${ }^{1}$ Zob. M. Pearlman: The Capture And Trial Of Adolf Eichmann. London 1961.
} 
Proces Eichmanna zajmuje niezwykle ważne miejsce zarówno $\mathrm{w}$ historii pamięci o Holokauście, jak i w historii mediów. Po raz pierwszy Holokaust był tak szeroko omawiany w telewizji, prasie i radiu. Pierwszy raz Zagłada Żydów została tak wyraźnie wyodrębniona $\mathrm{z}$ narracji łączącej wszystkie zbrodnie wojenne popełnione przez Niemców ${ }^{2}$. Liczne ofiary występujące $w$ roli świadków wyraźnie wskazywały winy i winnych. Ludzie z trzydziestu ośmiu krajów mogli śledzić relacje telewizyjną, radiową i prasową. Od początku o procesie Eichmanna mówiło się bardziej w kategoriach ważnego wydarzenia społecznego i historycznego niż procedury prawnej. Zarówno osoby przeciwne rozprawie, jak i jej zwolennicy odnosili się w swoich argumentach do metafory procesu jako spektaklu³. Prokurator generalny Gideon Hausner specjalnie dobierał świadków pod kątem efektu dramatycznego ich wystąpień.

Proces odbył się w teatrze Beit Ha’am, ponieważ zwykły sąd nie mógłby pomieścić wszystkich zaproszonych dziennikarzy. Jego przebieg był nagrywany przez Capital Cities Broadcasting Corporation, które następnie przekazywało materiał kanałom telewizyjnym na całym świecie. Co ciekawe, sam Izrael nie miał wtedy żadnego kanału telewizyjnego, więc Izraelczycy śledzili proces $\mathrm{w}$ radiu i prasie. Kasety $\mathrm{z}$ nagraniami przewożono samolotami do wszystkich krajów, które je zamówiły. Większość informacji podanych podczas rozprawy była wcześniej znana, przede wszystkim dzięki procesom norymberskim, jednak dopiero proces Eichmanna pozwolił na ich rzeczywiste rozpowszechnienie. Rozprawa sądowa sprowadzała się zatem nie do ustalania faktów, ale do ich performatywnego ponownego opowiedzenia. Transmisja telewizyjna pozwoliła na ożywienie historii, przedstawienie jej jako niedomkniętej, dziejącej się fragmenty procesu były pokazywane $\mathrm{w}$ wiadomościach telewizyjnych obok bieżących informacji. Rozprawie została nadana charakterystyczna dla telewizji logika „nażywości”4.

\section{Zeznania i relacje}

Świadek, któremu poświęcony jest ten artykuł, nazywał się Yehiel Dinur i urodził się 16 maja 1909 roku w Sosnowcu jako Yehiel Feiner. Przed wojną uczęszczał do jesziwy w Lublinie, był syjonistą i wydał tomik poezji w jidysz. Podczas wojny spędził dwa lata w Auschwitz. W 1945 roku wyjechał do Izraela i zaczął pisać powieści. Jego najsłynniejsza książka, Dom lalek, powstała w 1955

${ }^{2}$ Zob. J. ShanderR: While America Watches: Televising the Holocaust. New York-Oxford 1999.

${ }^{3}$ Por. tamże, s. 88.

${ }^{4}$ Zob. P. Auslander: Liveness. Performance in a Mediatized Culture. New York 1999. 
roku, a jej akcja toczy się głównie w domu publicznym w obozie koncentracyjnym $^{5}$. Dinur twierdził, że jest to pamiętnik jego siostry, która zginęła w obozie. Sześć lat później wydał powieść o wykorzystywaniu seksualnym chłopców przez nazistów, twierdząc, że opisuje losy swojego brata. Dinur tworzył literaturę graniczącą z pornografią, przepełnioną opisami aktów seksualnych i sadyzmem. Swoje książki podpisywał pseudonimem ${ }^{6}$ Ka-Tzetnik 135633, co pochodziło od słowa konzentrationslager (obóz koncentracyjny), skracanego do liter KZ i numeru obozowego ${ }^{7}$. Jego tożsamość została ujawniona dopiero podczas procesu Eichmanna. Początkowo Dinur nie chciał zeznawać, przekonał go do tego dopiero prokurator Hausner. Był niezwykle ważnym świadkiem, ponieważ jako jeden z niewielu spotkał Eichmanna podczas wojny.

Yehiel Dinur zeznawał podczas 68. sesji procesu Eichmanna. Pierwsze pytania dotyczyły jego tożsamości - kim jest, jak się nazywa, skąd pochodzi ${ }^{8}$. Już w tym momencie Dinur naruszył ramy procesu: stwierdził, że „Ka-Tzetnik 135633” to nie jego pseudonim, ponieważ nie uważa się za twórcę literatury, tylko za kronikarza „planety Auschwitz”. Następnie rozpoczął poetycki opis odległej planety, na której ludzie nie mają imion, a czas płynie inaczej niż na Ziemi. Kiedy doszedł do opisu ubrań mieszkańców tej planety, prokurator Hausner przerwał i pokazał mu pasiak z Auschwitz. Dinur potwierdził, że właśnie taki strój nosił. Potem wrócił do swojego przemówienia. Wyjaśnił, że za swoją misję uważa opowiedzenie historii tych, którzy zostali zamordowani w obozach, gdyż taką przysięgę im złożył. Twierdził, że musi to robić do momentu, kiedy ludzkość przebudzi się po ukrzyżowaniu narodu żydowskiego, tak jak kiedyś przebudziła się po ukrzyżowaniu jednego człowieka. Prokurator grzecznie spróbował mu zadać parę pytań, sędzia również zwrócił mu uwagę. Dinur jednak zachowywał się, jakby ich nie słyszał, mówił, że widzi swoich towarzyszy z Auschwitz, po czym wstał i zemdlał. Sesja nie mogła być kontynuowana, Dinur został wyniesiony na noszach.

Zanim przejdę do wyjaśnień omdlenia Yehiela Dinura, chciałabym oddać mu głos. W 1983 roku w programie telewizyjnym 60 minutes Mike’a Wallace’a Dinur wytłumaczył prowadzącemu swoje zachowanie podczas procesu'. Stwierdził, że

${ }^{5}$ Y. Dinur: Dom lalek. Przeł. A. Horodeński. Warszawa 1992.

${ }^{6}$ Podczas procesu Dinur twierdził, że nie jest to pseudonim ("It was not a pen name. I do not regard myself as a writer and a composer of literary material" - zapis 68. sesji procesu Adolfa Eichmanna w bazie The Nizkor Project. Dostępne w Internecie: http://www.nizkor.org/hweb/ people/e/eichmann-adolf/transcripts/Sessions/Session-068-01.html [data dostępu: 05.01.2018]), trudno jednak znaleźć inne określenie.

${ }^{7}$ Inna możliwa pisownia to K-Zetnik. Z kolei nazwisko Dinur (również zapisywane: Dinoor lub De-Nur) oznacza 'z ognia', czyli ‘ten, który przeżył ogień lub odrodził się jak feniks'.

${ }^{8}$ Zapis 68. sesji procesu Adolfa Eichmanna w bazie The Nizkor Project. Dostępne w Internecie: http://www.nizkor.org/hweb/people/e/eichmann-adolf/transcripts/Sessions/Session-068-01. html [data dostępu: 05.01.2018].

9 Por. G. Getz: The Measure of a Man: Twenty Attributes of a Godly Man. Ventura 2004, s. 141. 
zemdlał nie z powodu strachu czy powracających wspomnień, lecz dlatego, że zobaczył Eichmanna jako zwykłego człowieka i ta „prawda o człowieku” go przeraziła ${ }^{10}$. Przestraszył się, że on sam mógłby być zdolny do zbrodni. Ten głos jest ważny, mimo że można w nim rozpoznać uwewnętrznioną narrację Arendt na temat banalności zła i Eichmanna jako „zwykłego człowieka”. To, w jaki sposób pisarz tłumaczy swoje omdlenie, jest zgodne z tym, co mówił podczas procesu. W przemowie o „planecie Auschwitz” pojawia się podobna wizja obozów jak w książkach Dinura, umieszczających je w alternatywnej przestrzeni, niepozwalającej na racjonalne wskazanie ludzi za nie odpowiedzialnych. Postrzeganie Eichmanna jako zwykłego człowieka uniemożliwia podział na dwa równoległe światy, „tam” i „tu”.

Dosyć łatwo jest wytłumaczyć omdlenie Yehiela Dinura w kategoriach psychologicznych. Można u niego zdiagnozować dysocjację, czyli oddzielenie się podmiotu „od siebie”"11. Ponowne przeżycie doświadczeń wojennych podczas procesu okazało się zbyt trudne, dlatego to oddzielenie było potrzebne jako mechanizm obronny. Dysocjacja jest zerwaniem połączenia pomiędzy różnymi wydarzeniami z przeszłości, przez co wspomnienia stają się nieciągłe i pokawałkowane. Zerwanie może dotyczyć również połączenia pomiędzy aktualnymi wydarzeniami i ich emocjonalnym lub poznawczym znaczeniem, a także pomiędzy aktualnymi wydarzeniami i ich symboliczną reprezentacją. Jest często reakcją obronną w sytuacji traumatycznej, uruchamianą, by nie doświadczać bólu fizycznego lub psychicznego. Dysocjacja może przebiegać z zaburzeniami świadomości - osoby w tym stanie mogą mieć uczucie paraliżu, upadać, tracić kontakt z rzeczywistością.

Hannah Arendt przyjechała do Jerozolimy, żeby napisać reportaż z procesu dla „The New Yorker”. Podczas kolejnych sesji siedziała razem z innymi dziennikarzami w specjalnie dla nich przygotowanym pomieszczeniu i słuchała rozprawy przez słuchawki. Omdlenie Dinura opisała z dystansem graniczącym z pogardą. Stanowiło dla niej kolejny przejaw tego, że proces Eichmanna jest raczej spektaklem politycznym niż poważną rozprawą sądową. Arendt uznała zeznania składane przez Dinura za wyjątek w całym wydarzeniu wyreżyserowanym przez Hausnera, ale wyjątek potwierdzający jego charakter. W pracy Eichmann w Jerozolimie... przedstawia Dinura jako „autora kilku książek o Oświęcimiu opowiadających o zamtuzach, homoseksualistach i innych »ciekawiących ludzi rzeczach «"12. Dalej ze zgryźliwą ironią opisuje patetyczną przemowę pisarza,

${ }^{10} \mathrm{~W}$ kwestii omdlewania z lęku i znaczenia tego aktu ciekawym kontekstem może być analiza omdlenia Jerzego Andrzejewskiego autorstwa Marii Janion (Wobec zła. Chotomów 1989, s. 119).

${ }^{11}$ Por. Psychodynamic Diagnostic Manual. Eds. V. Lingiardi, N. McWilliams. Second edition. New York 2017, s. 179-180.

${ }^{12}$ H. Arendt: Eichmann w Jerozolimie. Rzecz o banalności zła. Przeł. A. Szostriewicz. Kraków 1987, s. 287. 
dodając bardzo liczne złośliwe komentarze. Niewątpliwie ma rację, uważając, że Dinur nie spełniał kryteriów „dobrego świadka” podczas procesu. Jego zeznania były chaotyczne, zbyt emocjonalne i nie na temat. Uderzający jest jednak pogardliwy język, którym posługuje się Arendt w opisie tej sytuacji. To ten sam ton, który stosuje, charakteryzując prokuratora Gideona Hausnera czy Dawida Ben-Guriona, jednak ci ostatni są w pozycji władzy, a Dinur występuje jako ofiara. Może jednak Dinurowi nie należy się specjalne traktowanie? Jego przemowę można traktować jak specjalnie wyreżyserowany i doskonale zrealizowany spektakl. W pewnym sensie podczas rozprawy to Eichmann był ofiarą (to jemu groziła kara śmierci), a Dinur stał po stronie silniejszego (Państwa Izrael).

Warto przytoczyć też inną relację z procesu Eichmanna. Jej autorem jest izraelski poeta Haim Gouri. Zwraca on uwagę na słowa, które wymamrotał prokurator po zemdleniu Dinura: "Nie spodziewałem się tego"13. Sam Gouri uważa, że ta sytuacja była do przewidzenia. Jego zdaniem problem polegał na tym, że kiedy większość świadków opisywała tylko swoją historię, dodając ją do ogólnego obrazu Zagłady, Yehiel Dinur próbował przedstawić ogólną prawdę o Holokauście i dotrzeć do jego esencji. Było to zgodne z zamierzeniem Hausnera, który zaplanował proces w ten sposób dla lepszego efektu dramaturgicznego $^{14}$. Próba przełamania formalnej rozprawy sądowej, $\mathrm{w}$ ramach której każdy świadek opowiada tylko część historii, i przeniesienia się z powrotem na planetę Auschwitz nie powiodła się. Omdlenie Dinura było zatem spowodowane nadmierną ambicją Hausnera, ale też zamiarem opowiedzenia wszystkiego przez mówiącego, bycia kimś więcej niż tylko kolejnym świadkiem. Dinur jednak nie miał wystarczająco dużo siły, by wykonać to zadanie.

\section{Płeć świadka}

Skłonność do omdleń jest reakcją przypisywaną kobietom, związaną z ich rzekomą słabością. Przed wojną figura Żyda często była kojarzona z tym, co kobiece $^{15}$. Klaus Theweleit, analizując zapiski żołnierzy z Freikorps, stwierdza, że oni również patrzyli na żydowskie ciała jak na ciała kobiece; widzieli je jako

${ }^{13}$ H. Gouri: Facing the Glass Booth. Transl. M. Swirsky. Detroit 2004, s. 128. Tłumaczenie cytatu - S.H.

${ }^{14} \mathrm{Z}$ protokołu procesu: "Attorney General: With the Court's permission, in view of the unfortunate incident that has taken place, I shall have to arrange the evidence on Auschwitz differently. It was intended that Mr. Dinur should give us a general description, so that the other witnesses could supplement it on various partial aspects" (zapis 68. sesji procesu Adolfa Eichmanna w bazie The Nizkor Project. Dostępne w Internecie: http://www.nizkor.org/hweb/people/e/ eichmann-adolf/transcripts/Sessions/Session-068-01.html [data dostępu: 05.01.2018]).

${ }^{15}$ Por. B. KefF: Antysemityzm. Niezamknięta historia. Warszawa 2013, s. 96 i 122. 
brudne, niebezpieczne i niemające ściśle określonych granic ${ }^{16}$. W opozycji do nich swoje aryjskie, męskie ciała widzieli jako zorganizowane, czyste, uporządkowane $^{17}$. Z kolei Sabrowie, czyli Żydzi urodzeni w Izraelu, stanowią przeciwieństwo cech kobiecych: budują państwo od podstaw na pustyni, są silni i nie zagraża im antysemityzm.

Co ciekawe, sam Dinur w swojej najsłynniejszej książce, czyli w Domu lalek z 1955 roku, przyjął kobiecą perspektywę. Powieść wypełniona jest graniczącymi z pornografią opisami tortur i zabiegów medycznych. Dinur, jak wspomniałam, twierdził, że oparł ją na pamiętniku swej siostry, która zginęła w obozie koncentracyjnym. Toteż długo czytano tę książkę jako autentyczny dokument dotyczący Zagłady, wielu Izraelczyków uczyło się z niej o historii Holokaustu. Była również rekomendowaną lekturą $\mathrm{w}$ izraelskich szkołach ${ }^{18}$. Nawet $\mathrm{w}$ polskim wydaniu z 1992 roku na czwartej stronie okładki zamieszczono informację, że opisuje prawdziwą historię. Następuje tu jednak kontaminacja autora i narratorki. Nota biograficzna w polskiej edycji brzmi następująco: „Ka-tzetnik 135633 - literacka legenda naszych czasów. Praktycznie anonimowa - tylko niewielu zna jej prawdziwe nazwisko - lecz wielka pisarka, może jedna z największych w naszym pokoleniu"19. Oczywiście można tę pomyłkę dotyczącą płci autora uznać za błąd $\mathrm{w}$ tłumaczeniu, ponieważ po angielsku w przytoczonych zdaniach płeć podmiotu nie ma znaczenia, jednak z jakichś przyczyn tłumacz założył, że forma żeńska będzie właściwa. W innym miejscu redaktorzy informują, że 135633 to numer obozowy autorki pamiętnika, na którym książka została oparta, i tym samym głównej bohaterki ${ }^{20}$. Ta pomyłka wydaje się interesująca w świetle wątpliwości dotyczących tego, czy Yehiel Dinur rzeczywiście miał siostrę. Dlaczego pisarz wybrał akurat kobietę jako alter ego, za pośrednictwem którego może opisać swoje doświadczenie obozowe? Dlaczego okropieństwa, które ją spotykają w książce, mają charakter seksualny? Być może postać kobieca pozwoliła Dinurowi do pewnego stopnia oddzielić się od opisywanej historii. Z kolei graniczące z pornografią opisy przemocy seksualnej można rozumieć jako sposób wyrażenia ekstremalnej traumy i upokorzenia więźnia ${ }^{21}$.

Omdlenie Dinura było aktem wyjścia poza ramy procesu, poza zasady ładu gwarantowanego przez prawo. Siłą rzeczy mdlejący zaburza porządek obrad

${ }^{16}$ Zob. K. Theweleit: Męskie fantazje. Przeł. M. Falkowski, M. Herer. Warszawa 2015.

${ }_{17} \mathrm{Na}$ temat nazistowskiego spojrzenia na kobiece ciało zob. J. Borowicz: Nagość i mundur. Ciało w filmie Trzeciej Rzeszy. Warszawa 2015.

${ }_{18}$ Por. D. Mikics: Holocaust Pulp Fiction. Dostępne w Internecie: http://www.tabletmag. com/jewish-arts-and-culture/books/97160/ka-tzetnik [data dostępu: 05.01.2018].

19 Y. Dinur: Dom lalek..., czwarta strona okładki.

${ }^{20}$ Podobna niejednoznaczność dotyczy ilustracji umieszczanych na okładkach niektórych wydań anglojęzycznych, przedstawiających kobietę z wytatuowanym na dekolcie napisem „Feld-Hure 135633".

${ }^{21}$ Oczywiście dopuszczalne są inne interpretacje, np. zakładające subwersywny charakter tekstów sadomasochistycznych. Nie będę jednak rozwijać tego wątku. 
i skupia na sobie uwagę publiczności. Prowadzi to do narzucającego się pytania: skoro rozprawa jest spektaklem, to kto jest głównym bohaterem - prokurator, sędzia, oskarżony czy świadkowie? Proces Eichmanna był historycznym momentem, ponieważ udzielił głosu ocalałym - więc może oni ${ }^{22}$ ? Nad całością czuwa sędzia Moshe Landau, a ton rozprawie nadaje prokurator Gideon Hausner. Jednak najbardziej przyciąga wzrok oskarżony, umieszczony w szklanej kabinie Eichmann. To jego czynów dotyczy, przynajmniej teoretycznie, proces. Kamera pokazuje go w dużym zbliżeniu, skupia się na jego minach i tiku nerwowym, jakby śledząc reakcje oskarżonego na zeznania świadków, można było odpowiedzieć na pytanie: jak to możliwe, że Zagłada się wydarzyła?

W wyprodukowanym przez BBC filmie o mechanizmach, które sprawily, że proces stał się widowiskiem telewizyjnym - The Eichmann Show, pojawia się teza, zgodnie z którą fakt, że nie uchwycono momentu zemdlenia Ka-Tzetnika, stanowi dowód na to, jak bardzo autor transmisji telewizyjnej był zaabsorbowany Eichmannem, a nie świadkami ${ }^{23}$. W filmie reżyser transmisji skupia się na oskarżonym zamiast dać miejsce świadkom. Emocjonalne zachowania świadków i widowni funkcjonują jako obrazy kontrastujące z beznamiętnymi reakcjami oskarżonego. Jednak na nagraniu widać, że moment omdlenia nie jest widoczny nie z powodu skupienia się kamery na Eichmannie, ale na składzie sędziowskim i na prokuratorze. Widz nie może zobaczyć samego momentu upadku, tylko leżące ciało, do którego podbiegają strażnicy.

Yehiel Dinur twierdzi, że w obozie był muzułmanem ${ }^{24}$. Muzułman to figura opisywana przez Giorgia Agambena jako pozbawiona człowieczeństwa i podmiotowości, nagie życie. To ostateczny stopień zniszczenia człowieka przez obóz koncentracyjny i nazistowską biopolitykę. Koncepcja Agambena spotkała się $\mathrm{z}$ oporem wielu historyków ${ }^{25}$, dla których takie spojrzenie na muzułmana jest powtórzeniem spojrzenia oprawcy i ignoruje liczne przejawy podmiotowości oraz oporu ze strony więźnia. Równocześnie można potraktować ją nie jako figurę zawierającą autentyczne doświadczenia konkretnych ludzi, ale konstrukt ukazujący cel nazistowskiej biopolityki. Mdlejący Dinur jednocześnie stawia opór (zaburzając porządek procesu) i daje się unicestwić. Jego bunt jest cielesny, fizyczny, ponieważ inny jego rodzaj nie jest możliwy.

${ }^{22}$ Arendt krytykuje koncentrację podczas procesu Eichmanna na świadkach, a nie na oskarżonym i jego czynach.

${ }^{23}$ The Eichmann Show. Reż. P.A. Williams. Scen. S. Block. Wielka Brytania 2015.

24 "This oath was the armour with which I acquired the supernatural power, so that I should be able, after time - the time of Auschwitz - the two years when I was a Musselman, to overcome it" (zapis 68. sesji procesu Adolfa Eichmanna w bazie The Nizkor Project. Dostępne w Internecie: http://www.nizkor.org/hweb/people/e/eichmann-adolf/transcripts/Sessions/Session-068-01.html [data dostępu: 05.01.2018]).

${ }^{25}$ Por. E. Domańska: Muzulman: świadectwo i figura. W: W sprawie Agambena. Konteksty krytyki. Red. Ł. Musiae, M. Ratajczak, K. Szadkowski, A. Żychliński. Poznań 2010, s. 233260. 
Kim jednak jest ten mdlejący człowiek, próbujący przedstawić swoją historię przed dawnym oprawcą i całym swoim ciałem stawiający opór wobec sytuacji, w której się znalazł? Można uznać, że spotykają się w nim trzy osoby: izraelski pisarz, obozowy muzułman i kobieta-ofiara (Daniela). W postaci Ka-Tzetnika granice między tymi trzema figurami się zacierają. Występuje on w roli pisarza, który opisał Zagładę. Jednocześnie emocjonalnie ulega regresowi i cofa się do czasu uwięzienia w obozie (na planecie Auschwitz), gdzie był muzułmanem. Zarazem można go utożsamić z Danielą, bohaterką jego najistotniejszej książki, kobietą poddawaną torturom i przemocy seksualnej. Omdlenie jest zarówno aktem, w którym te trzy postaci się łączą, jak i wydarzeniem wywołanym przez to niemożliwe połączenie. Dinur mdleje i ten akt jest pewną formą aktualizacji, odgrywania i odtworzenia historii. Zgodnie z teorią Rebekki Schneider rekonstrukcje historyczne są alternatywnym wobec narracyjnego sposobem opowiadania o przeszłości ${ }^{26}$. Jako praktyki cielesne pozwalają na przeżycie historii w czasie teraźniejszym i przekazanie jej innym. Cielesną transmisję wiedzy Schneider nazywa „body-to-body transmission”27. Teoria badaczki zakłada, że performans może kwestionować linearność historii, ponieważ w jego ramach wydarzenie ma charakter cykliczny i niedokończony. Logika performansu przeciwstawia się logice archiwum, które zdaniem Schneider zawsze jest patriarchalne. To ugenderowienie tradycyjnej narracji historycznej podkreśla subwersywność gestu Dinura: jego omdlenie było działaniem kobiecym, ponieważ performans zawsze ma taki charakter.

\section{Logika procesu}

Zastanawiające jest, że Hannah Arendt nie przeżyła empatycznie sceny omdlenia Dinura. Oczywiście domyślenie się, dlaczego jej odczucia i reakcje były akurat takie, jest niemożliwe, można jednak zgadywać. Od pierwszych stron Eichmanna w Jerozolimie... widać, że Arendt zależy na wykazaniu błędów popełnianych przez Państwo Izrael. Usiłuje być surowym sędzią, dystansując się od swojego żydowskiego pochodzenia, które mogłoby zakłócić jej obiektywizm. Jej opis procesu jest bezwzględny, podobnie podchodzi do samych ofiar występujących $\mathrm{w}$ roli świadków. Nie chcę zagłębiać się w tajniki tożsamości narodowej Arendt, można jednak założyć, że jej nadmierny krytycyzm wynika $\mathrm{z}$ emocjonalnego zaangażowania. Jednocześnie nie bez znaczenia jest pozycja,

${ }^{26}$ Por. R. SchneIder: Performing Remains: Art and War in Times of Theatrical Reenactment. New York 2011.

27 Tamże, s. 99. 
z której filozofka oglądała proces. Znajdowała się w zamkniętej kabinie dla dziennikarzy, rozprawę widziała na ekranie i słuchała jej przez słuchawki. Przestrzeń, w której przebywała, ułatwiała zdystansowanie się i obserwowanie z chłodnym nastawieniem. Jeżeli dla Arendt proces był spektaklem, to nie tylko jako widowisko, ale też jako coś, co można bezpiecznie oglądać z perspektywy widowni. Dwuznaczność słowa „spektakl” jest nieprzypadkowa. Kiedy filozofka go używa, myślimy o jej poglądach na temat izraelskiego systemu sprawiedliwości (reżysera spektaklu). Jednak ten wyraz równie dużo mówi nam o pozycji, w której Arendt stawia się wobec rozprawy sądowej.

Do kwestii procesu jako spektaklu można podejść od jeszcze innej strony. Shoshana Felman pisze, że znaczenie procesu Eichmanna nie polegało na wyrażeniu traumy językiem prawa i sądownictwa, ale właśnie na porażce tego zadania i na publicznym zademonstrowaniu jego nieadekwatności ${ }^{28}$. Dlatego proces ten jest tak ważnym momentem w historii pamięci o Zagładzie. Wystąpienie Dinura w roli świadka stanowi najlepszy przykład tej porażki. Jednak jego niedopasowanie do zasad procesu ma jeszcze jeden aspekt: Dinur myśli o Auschwitz w czasie teraźniejszym, cały czas czuje się uwięziony w obozie. Z kolei rolą prawa jest ustalanie faktów $\mathrm{w}$ czasie przeszłym, $\mathrm{z}$ odniesieniem do minionych wydarzeń. Stąd omdlenie Dinura dobrze wpisało się w transmisję telewizyjną rozprawy - nie tylko samo było wydarzeniem medialnym, ale też wskazało na niedokończony charakter historii, na konieczność ciągłego odtwarzania minionych zdarzeń. Stało się więc nie tylko znakiem konkretnego trybu myślenia o Zagładzie, ale także nowego sposobu przedstawiania historii w telewizji, w formule zbliżonej do prezentowania bieżących wydarzeń.

Proces Eichmanna był istotny również dlatego, że zapocząatkował nową formę postrzegania ocalałych z Zagłady. Tuż po wojnie w Izraelu w ogóle się o nich nie mówiło, traktowano ich wręcz pogardliwie. Postrzegano ich jako ofiary, które poddały się, nie stawiając oporu. Uważano ich też za niegodnych szacunku, ponieważ zostali w Europie, zamiast przyjechać od razu do Palestyny, żeby budować od podstaw nowe Państwo Izrael. Proces Eichmanna udzielił głosu ocalałym i pozwolił im opowiedzieć swoją historię, przez co mogli odzyskać utraconą w oczach innych godność. Dinur pozwolił sobie na więcej niż inni świadkowie - nie tylko skorzystał z prawa głosu, ale także całym swoim ciałem wyraził to, na co nie wystarczyło mu słów. Tym samym przemówił nie jedynie jako świadek, czyli ktoś, kto widział czyny, o które oskarżono Eichmanna. Przemówił jako osoba, która przeżyła to, czemu winny był Eichmann - jako muzułman, zniszczony, poniżony do tego stopnia, że jego kondycję można opisać tylko za pomocą metafory gwałtu na kobiecie. Stąd jego niebywałe znaczenie dla pamięci o procesie. Po tak silnym emocjonalnie wystąpieniu musiało nastąpić równie

${ }^{28}$ Por. Sh. Felman: The Juridical Unconscious: Trials and Traumas in the Twentieth Century. Cambridge 2002, s. 111. 
intensywne zakończenie. Niestety obecnie proces Eichmanna postrzegamy głównie przez pryzmat relacji Arendt, traktując autorkę jako neutralną obserwatorkę, przez co zemdlenie Ka-Tzetnika traci swój wizualny, performatywny i emocjonalny charakter.

\section{Bibliografia}

Arendt H.: Eichmann w Jerozolimie. Rzecz o banalności zła. Przeł. A. Szostriewicz. Kraków 1987.

Auslander P.: Liveness. Performance in a Mediatized Culture. New York 1999.

Borowicz J.: Nagość i mundur. Ciało w filmie Trzeciej Rzeszy. Warszawa 2015.

Dinur Y.: Dom lalek. Przeł. A. Horodeński. Warszawa 1992.

DomańsKa E.: Muzutman: świadectwo i figura. W: W sprawie Agambena. Konteksty krytyki. Red. Ł. Musiae, M. Ratajczak, K. Szadkowski, A. Żychliński. Poznań 2010, s. 233-260.

Felman Sh.: The Juridical Unconscious: Trials and Traumas in the Twentieth Century. Cambridge 2002.

Getz G.: The Measure of a Man: Twenty Attributes of a Godly Man. Ventura 2004.

Gouri H.: Facing the Glass Booth. Transl. M. Swirsky. Detroit 2004.

Hershкowitz I.: Asmodeus and Nucleus on Planet Auschwitz: Katzetnik's Theological and Demonological Kabbalah. Dostępne w Internecie: https://www.academia. edu/3316135/Asmodeus_and_Nucleus_on_Planet_Auschwitz_Katzetnik_s_Theological_and_Demonological_Kabbalah [data dostępu: 05.01.2018]. [Referat wygłoszony na konferencji "Ka-Tzetnik: The Impact of the First Holocaust Novelist in Israel and Beyond", University of Calgary, 10-12 marca 2013 roku].

Janion M.: Wobec zła. Chotomów 1989.

Keff B.: Antysemityzm. Niezamknięta historia. Warszawa 2013.

Mikics D.: Holocaust Pulp Fiction. Dostępne w Internecie: http://www.tabletmag.com/ jewish-arts-and-culture/books/97160/ka-tzetnik [data dostępu: 05.01.2018].

Pearlman M.: The Capture And Trial Of Adolf Eichmann. London 1961.

Pinchevsky A., Brand R.: Holocaust Perversions: The Stalags Pulp Fiction and the Eichmann Trial. "Critical Studies in Media Communication" 2007, Vol. 24, Issue 5, s. 387-407.

Psychodynamic Diagnostic Manual. Eds. V. Lingiardi, N. McWilliams. Second edition. New York 2017.

SchneIder R.: Performing Remains: Art and War in Times of Theatrical Reenactment. New York 2011.

Shandler J.: While America Watches: Televising the Holocaust. New York-Oxford 1999. Theweleit K.: Męskie fantazje. Przeł. M. Falkowski, M. Herer. Warszawa 2015. 
Sara Herczyńska

\section{Return to the Planet of Auschwitz}

Yehiel De-Nur's Collapse as the Key Moment in Creating the Memory of the Shoah

\section{Summary}

Yehiel De-Nur's collapse was one of the most significant moments during the Eichmann trial. A Holocaust survivor and a writer, De-Nur was a witness at the trial. The article is an attempt at investigating his fainting on recordings and in accounts of the trial and at interpreting it in the performative and visual context.

Key words: the Eichmann trial, Yehiel De-Nur, Hannah Arendt, fainting, performance, Holocaust, Israel 